(2) Open Access Full Text Article

ORIGINAL RESEARCH

\title{
Expression of Lin28 is correlated with prognosis and expression of HER-2 and steroid receptors in breast cancer
}

This article was published in the following Dove Medical Press journal:

OncoTargets and Therapy

\section{Chaoyang Xu \\ Shuxun Jin \\ Liming Huang}

Department of Breast and Thyroid Surgery, Shaoxing People's Hospital (Shaoxing Hospital, Zhejiang University School of Medicine), Zhejiang, China
Correspondence: Liming Huang; Chaoyang $\mathrm{Xu}$

Department of Breast and Thyroid Surgery, Shaoxing People's Hospital (Shaoxing Hospital, Zhejiang University School of Medicine), No. 568

Zhongxing Road, Yuecheng District,

Shaoxing 312000, China

Tel +865758822 946I;

+8657588229162

Email shaoxinghlm@I26.com;

xuchy@usx.edu.cn
Objective: Cumulative data from clinical trials suggest that Lin28 may contribute to poor survival in breast cancer patients. The purpose of this study was to investigate the relationship between Lin28 expression and breast cancer patients' clinicopathological parameters.

Methods: Data from a total of 291 breast cancer patients were collected in this study. The expression level of Lin28 was assessed by immunohistochemical staining. The correlation of Lin28 expression and clinicopathological parameters was statically evaluated and the prognostic significance of Lin28 expression was assessed by univariate and multivariate analyses.

Results: One hundred and eight out of 291 (37.1\%) breast cancer specimens showed Lin28 protein positive expression, while the remaining 183 specimens showed negative expression. Positive expression of Lin28 was associated with lymph node metastases $(P<0.001)$, HER-2 $(P=0.024)$, estrogen receptor $(P=0.039)$, and progesterone receptor $(P=0.027)$. Kaplan-Meier analysis showed that Lin 28 positive expression showed lower overall survival rates compared with $\operatorname{Lin} 28$ negative patients $(P=0.019)$. In the multivariate analysis, $\operatorname{Lin} 28$ remained a significant independent prognostic factor $(P=0.038)$ for overall survival rates.

Conclusion: Lin 28 expression was associated with advanced disease stage and subtype in breast cancer patients, and Lin28 expression may serve as an independent prognostic factor. These data indicate that Lin28 may play a major role in the therapeutic management of breast cancer.

Keywords: breast cancer, Lin28, prognosis, estrogen receptor

\section{Introduction}

Currently breast cancer, which is a heterogeneous disease, remains one of the most common cancers in Chinese women. ${ }^{1}$ Identification of new biologic targets in patients with breast cancer may contribute to improvement in outcome. ${ }^{2}$

Lin28 is a highly conserved RNA-binding protein, and it is expressed in various human epithelial-type neoplasia, such as lung cancer, ${ }^{3}$ ovarian cancer, ${ }^{4}$ hepatocellular cancer, ${ }^{5}$ and colorectal cancer. ${ }^{6}$ Previously, our study showed that high expression of Lin28 is a poor prognostic factor in gastric cancer, ${ }^{7}$ and it is significantly associated with lymph node metastasis in colorectal cancer. ${ }^{6}$ Recent studies have shown that Lin28 has two RNA-binding motifs, which blocks let-7 miRNA family processing, and there have been many reports of let- 7 miRNAs that could reduce self-renewing tumor-initiating cells and increase differentiation. Thus, blocking Lin28 pathways may provide potential therapy options for patients with colorectal cancer. ${ }^{6}$ This prompted us to evaluate Lin28 status in breast cancer.

Recent studies suggest that Lin28 expression was found to be correlated with estrogen receptor (ER) and HER-2 expression. ${ }^{8}$ Lin28 binds to target sites, leading 
to impact of ER and HER-2 protein expression in breast cancer. Several studies have examined Lin28 expression in breast cancer, but results remain inconclusive and the relationship between Lin28 expression and prognosis and subtype remains unclear.

The objective of the current study was to investigate Lin28 protein expression level in breast cancer specimens and to evaluate the clinical significance of Lin28 expression by its correlation with clinicopathological parameters and subtype. To our knowledge, no studies have been performed to characterize the expression of Lin28 in subtype in clinical breast cancer specimens previously.

\section{Patients and methods}

\section{Case selection}

Breast cancer specimens were obtained from 291 patients who underwent surgery. None of the patients received any neoadjuvant treatment for breast cancer before undergoing surgery in the Department of Breast and Thyroid Surgery, Shaoxing People's Hospital (Shaoxing Hospital, Zhejiang University School of Medicine) between January 2011 and December 2013. All patients provided informed consent as per the guidelines of the Hospital Ethics Committee. All patients were female, aged from 31 to 77 years old (mean \pm 53.8 years old), and included 196 modified radical mastectomy patients and 95 who underwent conservative surgery. Correlation between expression of Lin28 and clinicopathologic parameters including age, tumor size, tumor grade, lymph node metastasis, and expression level of ER, progesterone receptor (PR), HER-2, and Ki67 was evaluated. The pathologic features of the specimens were classified based on the seventh edition of the International Union against Cancer and the American Joint Committee on Cancer staging manuals.

\section{Ethics approval}

The Ethics Committee of The Shaoxing People's Hospital (Shaoxing Hospital, Zhejiang University School of Medicine) approved this study before initiation. Written informed consent and verbal informed consent are both acceptable to Ethics Committee of The Shaoxing People's Hospital. All the patients or their guardians provided written informed consent or orally agreed to the informed consent via phone (which was recorded). This study was performed in compliance with the Declaration of Helsinki.

\section{Immunohistochemistry}

Immunohistochemical analysis for Lin28, ER, PR, HER-2, and Ki67 expression was performed on formalin-fixed, paraffin-embedded sections of breast cancer specimens. The method was taken from our previously published paper. ${ }^{7}$ Briefly, the slides were heated for 15 minutes, for antigen retrieval, immersed in $10 \mathrm{mM}$ citric buffer. The slides were incubated with Lin28 (rabbit polyclonal, H-44, 1:100; Santa Cruz Biotechnology Inc., Dallas, TX, USA) for 1 hour in slides. Then, slides were incubated with the EnVision-HRP complex (undiluted, Dako Denmark A/S, Glostrup, Denmark) for 1 hour. After staining, the sections were visualized with diaminobenzidine, and counterstained with hematoxylin. For negative controls, the Lin28 was replaced with PBS. Positive control was gastric cancer tissue known to exhibit high levels of Lin28.

Immunohistochemical analysis reported in this study was carried out in a single laboratory. The expression of the proteins was assessed semi-quantitatively by estimating the percentage of tumor cells with positive cytoplasm staining on whole tumor slides. Slides were reviewed and scored independently by two experienced pathologists. Each slide was examined in its entirety under a light microscope, and initially a proportion score was assigned, which represented the estimated proportion of positive tumor cells $(0$, none; $1,0 \%-10 \% ; 2,10 \%-50 \% ; 3,50 \%-100 \%)$. The expression level of Lin28, ER, PR, and HER-2 was taken from a previously published assay. ${ }^{9}$ An intensity score was assigned which represented the average intensity of the positive tumor cells ( 0 , none; 1 , weak; 2 , intermediate; and 3 , strong). The proportion and intensity scores were then multiplied to obtain a total score, which ranged from 0-9, and Lin28, ER, PR, and HER-2 protein positive expression was defined as total score $\geq 2$. The evaluation criteria for Ki67 expression were interpreted based on the percentage of positive tumor cells: score $0=$ no staining; score $1+=$ up to $14 \%$ staining; score $2=$ more than $14 \%$ staining of tumor cells. A score of 0 was considered negative.

\section{Follow-up}

All patients were followed-up until death or until the date of last follow-up of 15 September 2018. Thirty-two patients $(11.0 \%)$ died during the follow-up period, and the median follow-up interval was 66.1 months (range: 10-91 months).

\section{Statistical analysis}

Descriptive studies were conducted by using the statistical program SPSS 15.0 for windows. Patients' characteristics were analyzed using the two-tailed chi-squared test, and the two-tailed Student's $t$-test was used to evaluate the 
association between Lin28 expression and clinicopathologic parameters and steroid receptors. The analysis of patient survival curves was compared using Kaplan-Meier method. Multivariate analyses were done using logistic regression and Cox's proportional hazards model. The accepted level of significance was set as $P<0.05$. Two-sided statistical tests were used in all the previously mentioned analyses.

\section{Results \\ Positive expression of Lin28 protein was found in breast cancer tissues}

Positive expression of Lin28 protein was found in 108 of 291 (37.1\%) breast cancer tissues. Lin28 staining was predominantly localized in the cytoplasm in all 108 Lin28 positive breast cancer specimens (Figure 1). The correlation
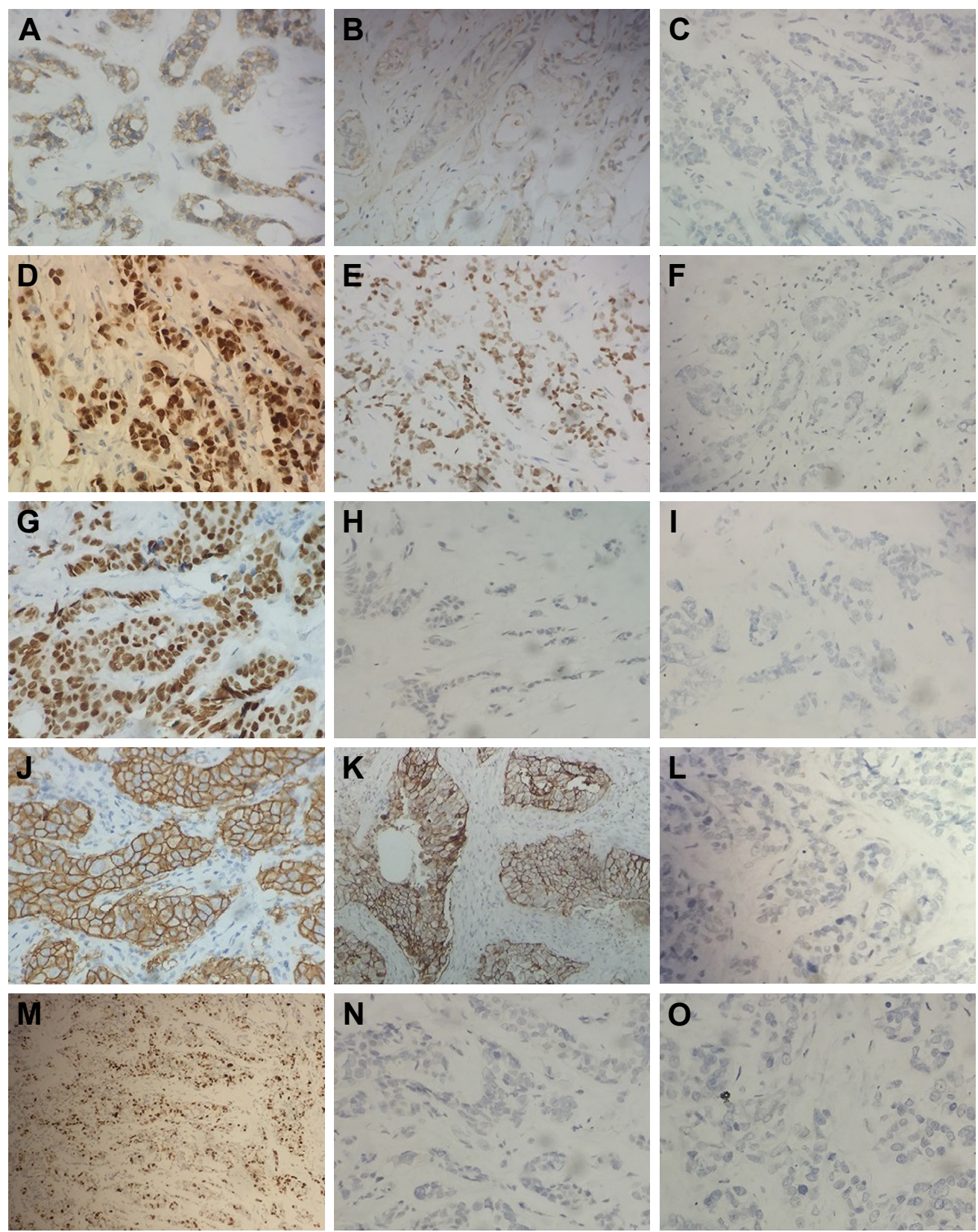

Figure I Immunohistochemical analysis of Lin28, ER, PR, HER-2, and Ki67 expression in breast cancer specimens.

Notes: (A) Lin28 high expression cytoplasmic staining in tumor cell. (B) Lin28 low expression cytoplasmic staining in tumor cell. (C) Lin28 negative expression cytoplasmic staining in tumor cell. (D) ER high nuclear staining in the tumor cell. (E) ER low nuclear staining in the tumor cell. (F) ER negative nuclear staining in the tumor cell. (G) PR high nuclear staining in the tumor cell. (H) PR low nuclear staining in the tumor cell. (I) PR negative nuclear staining in the tumor cell. (J) HER-2 high cytoplasmic staining in the tumor cell. (K) HER-2 low cytoplasmic staining in the tumor cell. (L) HER-2 negative cytoplasmic staining in the tumor cell. (M) Ki67 high nuclear staining in the tumor cell. (N) Ki67 low nuclear staining in the tumor cell. (O) Ki67 negative nuclear staining in the tumor cell. Original magnification: $\times 50$.

Abbreviations: ER, estrogen receptor; PR, progesterone receptor. 
Table I Clinicopathologic features of 29/ breast cancer patients

\begin{tabular}{|c|c|c|c|}
\hline & \multicolumn{2}{|c|}{ Lin28 expression } & \multirow[t]{2}{*}{$P$-value } \\
\hline & $\begin{array}{l}\text { Positive } \\
(n=108)\end{array}$ & $\begin{array}{l}\text { Negative } \\
(n=183)\end{array}$ & \\
\hline Age & $53.4 \pm 9.4$ & $54.1 \pm 10.3$ & 0.571 \\
\hline Tumor grade & & & 0.065 \\
\hline 1 & $21(19.4)$ & $27(14.8)$ & \\
\hline 2 & $27(25.0)$ & $70(38.3)$ & \\
\hline 3 & $60(55.6)$ & $86(47.9)$ & \\
\hline Tumor size $(\mathrm{cm})$ & & & 0.099 \\
\hline$<2$ & $45(41.7)$ & $100(54.6)$ & \\
\hline$\geq 2$ and $<5$ & $59(54.6)$ & $77(42.1)$ & \\
\hline$\geq 5$ & $4(3.7)$ & $6(3.3)$ & \\
\hline Lymph node metastasis & & & $<0.001$ \\
\hline 0 & $32(29.6)$ & $118(19.4)$ & \\
\hline$\geq \mid$ and $<3$ & $49(45.3)$ & $36(19.4)$ & \\
\hline$\geq 4$ and $<9$ & $14(13.0)$ & $23(19.4)$ & \\
\hline$\geq 10$ & $13(12.1)$ & $6(19.4)$ & \\
\hline ER & & & 0.010 \\
\hline Negative & $47(19.4)$ & $52(19.4)$ & \\
\hline Positive & $61(19.4)$ & 131 (19.4) & \\
\hline PR & & & $<0.001$ \\
\hline Negative & $55(19.4)$ & $54(19.4)$ & \\
\hline Positive & $53(19.4)$ & $129(19.4)$ & \\
\hline HER-2 & & & 0.151 \\
\hline Negative & $68(19.4)$ & I3I (19.4) & \\
\hline Positive & $40(19.4)$ & $21(19.4)$ & \\
\hline Ki67 & & & 0.634 \\
\hline$<14$ & $20(19.4)$ & $30(19.4)$ & \\
\hline$\geq 14$ & $88(19.4)$ & $153(19.4)$ & \\
\hline
\end{tabular}

Notes: Data are presented as mean \pm SD or $\mathrm{n}$ (\%).

Abbreviations: ER, estrogen receptor; PR, progesterone receptor.

between Lin28 expression and clinicopathological parameters of 291 breast cancer cases are shown in Table 1.

Lin28 expression was correlated with lymph node metastasis group. However, no difference was found between positive and negative groups regarding age, tumor size, and tumor grade (Table 1).

\section{Lin28 expression correlation with HER-2 and steroid receptors}

As shown in Table 2, the number of patients with positive Lin28 expression was significantly correlated with ER $(P=0.010)$ and PR $(P<0.001)$. Lin28 expression was high in HER-2 positive group, but there was no statistically significant difference between HER-2 positive and negative groups. In addition, no difference was found between positive and negative groups regarding Ki67.

\section{Univariate analysis}

In univariate analysis, tumor size, lymph node metastasis, ER, PR, and Lin28 expression were associated with overall survival (Table 2). Based on the expression level of Lin28, the mean overall survival time for Lin28 positive expression group was 79.6 months and for negative Lin28 expression group, 89.4 months, respectively. The difference in survival was significant $(P<0.001)$ (Figure 2$)$. These data suggest that Lin28 positive expression is correlated with poor prognosis.

\section{Multivariate analysis}

The following parameters were entered into a multivariate analysis: age, tumor size, lymph node metastasis, tumor grade, and expression level of Lin28, ER, PR, HER-2, and Ki67. In terms of overall survival rates, lymph node metastasis, Lin28, and ER expression were independent predictors, which suggests that Lin28 expression served as an independent prognostic factor (Table 2).

\section{Discussion}

Currently, breast cancer remains one of the most common cancers worldwide, and one of the most common cancers among Chinese women. Lin28's ability to reprogram human somatic cells to induce pluripotent stem cells has been confirmed. ${ }^{10}$

Table 2 Results of univariate and multivariate analysis for prognostic factors $(n=291)$

\begin{tabular}{|c|c|c|c|}
\hline & \multirow[t]{2}{*}{ Univariate analysis $P$-value } & \multicolumn{2}{|c|}{ Multivariate analysis } \\
\hline & & HR (95\% Cl) & $P$-value \\
\hline Lin28 (positive vs negative) & $<0.001$ & $3.47 \mid(1.509-7.988)$ & 0.003 \\
\hline ER (positive vs negative) & $<0.001$ & $0.408(0.179-0.927)$ & 0.032 \\
\hline Lymph node metastasis ${ }^{a}$ & $<0.001$ & I.I23 (I.07I-I.I77) & $<0.001$ \\
\hline Tumor size $^{\mathrm{a}}$ & 0.045 & & \\
\hline PR (positive vs negative) & 0.002 & & \\
\hline HER-2 (positive vs negative) & 0.186 & & \\
\hline $\mathrm{Ki} 67(\geq 15$ vs $<14)$ & 0.085 & & \\
\hline Age $(\geq 50$ vs $<50)$ & 0.912 & & \\
\hline Tumor grade & 0.275 & & \\
\hline
\end{tabular}

Notes: ${ }^{a}$ Consecutive variables; others were categorized variables.

Abbreviations: ER, estrogen receptor; PR, progesterone receptor. 


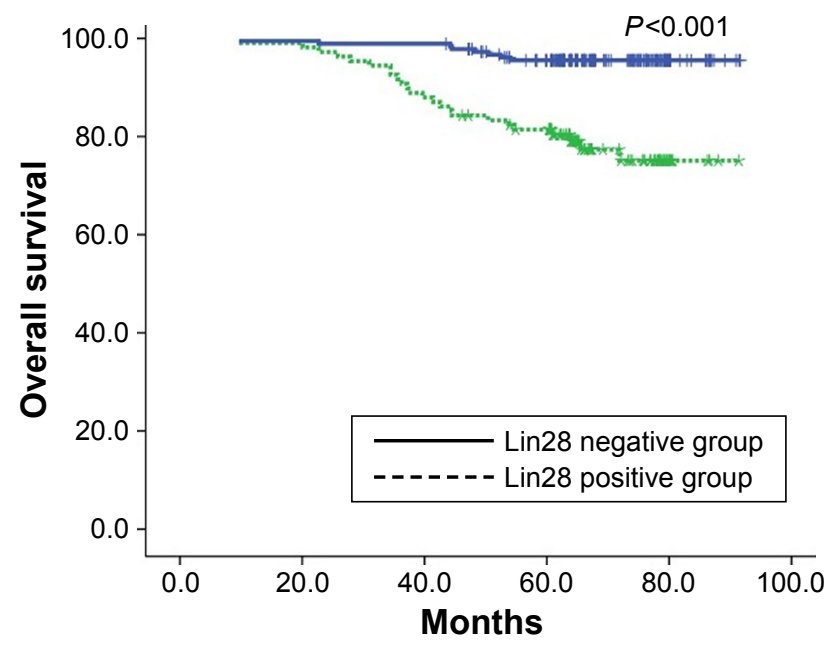

Figure 2 Kaplan-Meier survival analysis stratified according to Lin28 expression in patients with breast cancer, the mean overall survival time for Lin 28 positive expression group was 79.6 months and for negative Lin28 expression group 89.4 months $(P<0.001)$.

Recently, evidence has suggested that Lin 28 was an independent negative prognostic factor in androgen receptor positive breast cancer patients. ${ }^{11}$ Our previous paper indicated that $\operatorname{Lin} 28$ was expressed in gastric cancer tissues and Lin 28 protein positive expression was correlated with poor outcome (using immunohistochemical staining in 229 gastric carcinoma patients). ${ }^{7}$ This prompted us to hypothesize that Lin 28 may be correlated with advanced disease and subtype in breast cancer.

This study elucidated the correlation between Lin28 positive expression and breast cancer, by immunohistochemistry. The results showed that $37.1 \%$ (108 of 291) of cases had Lin28 protein positive expression. Lin28 expression was significantly higher in the lymph node metastasis group and correlated with prognosis. These features indicated advanced disease with aggressive characteristics, which is similar to previous studies. ${ }^{11-13}$

Positive Lin28 expression in breast cancer specimens showed a powerful adverse prognostic effect in our study. The effect of Lin28 expression status was independent of other known predictors, such as tumor size, lymph node metastasis, tumor grade, and expression level of ER, PR, HER-2, and Ki67. It is not yet clear how Lin28 expression affects advanced disease in breast cancer, but the Lin28/let-7 pathway is considered to impact cell proliferation and cell growth, which may explain this. ${ }^{3,14,15}$

Recent evidence suggests that Lin 28 modulates gene expression by altering translation, Peng et al showed that Lin28 blocks let-7 production, and de-represses H19 expression in breast cancer cells. ${ }^{16}$ Lin28 expression was found to be correlated with ER status and HER-2 status. ${ }^{8,17}$
Several studies have examined the relationship between Lin28 and ER, but results remain unclear. This study found that Lin28 expression was inversely correlated with ER and PR. However, the previous study showed Lin 28 expression was found to be positively correlated with ER status, by using 26 cases of breast cancer. ${ }^{18}$ It may be that the small number of cases in that study limited the statistical power of prediction. The reason why Lin28 is inversely correlated with ER and PR status is unknown. It has been speculated that Lin28 is an RNA-binding protein, which can regulate the translation or stability of mRNAs of ER and PR. Some studies found that Lin28 can bind to target sites, leading to enhanced HER-2 expression. In this study, Lin28 was highly expressed in the HER-2 positive group compared to negative group, although there was no statistically significant difference. A similar result was presented in another study. ${ }^{11}$

\section{Conclusion}

In summary, the study demonstrated that Lin 28 expression may play a role in oncogenesis and may serve as a biomarker for prognosis. This study suggests that Lin 28 expression was correlated with ER status and HER-2 status. Based on our findings, Lin 28 protein could be a potential target for the treatment of breast cancer. The results of this study provide new knowledge of Lin28 as a potential future prospect for breast cancer treatment.

\section{Acknowledgments}

This study was supported by grants from the National Natural Science Foundation of China (grant no. 81341135), Zhejiang nonprofit technology applied research projects of China (grant no. 2016C33226), Shaoxing nonprofit technology applied research projects of China (grant nos. 2017B70037 and 2017QN002).

\section{Disclosure}

The authors report no conflicts of interest in this work.

\section{References}

1. Wang L, Hong BY, Kennedy SA, et al. Predictors of unemployment after breast cancer surgery: a systematic review and meta-analysis of observational studies. J Clin Oncol. 2018;36(18):1868-1879.

2. Mørch LS, Skovlund CW, Hannaford PC, Iversen L, Fielding S, Lidegaard $\varnothing$. Contemporary hormonal contraception and the risk of breast cancer. N Engl J Med. 2017;377(23):2228-2239.

3. Yin J, Zhao J, Hu W, et al. Disturbance of the let-7/Lin28 double-negative feedback loop is associated with radio- and chemo-resistance in non-small cell lung cancer. PLoS One. 2017;12(2):e0172787.

4. Hsu KF, Shen MR, Huang YF, et al. Overexpression of the RNA-binding proteins Lin28B and IGF2BP3 (IMP3) is associated with chemoresistance and poor disease outcome in ovarian cancer. Br J Cancer. 2015; 113(3):414-424. 
5. Qiu JL, Huang PZ, You JH, et al. Lin28 expression and prognostic value in hepatocellular carcinoma patients who meet the Milan criteria and undergo hepatectomy. Chin J Cancer. 2012;31(5):223-232.

6. Tu HC, Schwitalla S, Qian Z, et al. Lin 28 cooperates with Wnt signaling to drive invasive intestinal and colorectal adenocarcinoma in mice and humans. Genes Dev. 2015;29(10):1074-1086.

7. Xu C, Shen J, Xie S, Jiang Z, Huang L, Wang L. Positive expression of Lin28 is correlated with poor survival in gastric carcinoma. Med Oncol. 2013;30(1):382.

8. Wang Q, Zhou J, Guo J, et al. Lin28 promotes HER2 expression and Lin28/Her2 predicts poorer survival in gastric cancer. Tumour Biol. 2014;35(11):11513-11521.

9. Wang L, Jiang Z, Sui M, Shen J, Xu C, Fan W. The potential biomarkers in predicting pathologic response of breast cancer to three different chemotherapy regimens: a case control study. BMC Cancer. 2009;9:226.

10. Okita K, Yamakawa T, Matsumura Y, et al. An efficient nonviral method to generate integration-free human-induced pluripotent stem cells from cord blood and peripheral blood cells. Stem Cells. 2013;31(3):458-466.

11. Shen H, Yang Y, Zhao L, Yuan J, Niu Y. LIN28A and androgen receptor expression in ER-/Her2+ breast cancer. Breast Cancer Res Treat. 2016;156(1):135-147.
12. Xiong H, Zhao W, Wang J, et al. Oncogenic mechanisms of Lin28 in breast cancer: new functions and therapeutic opportunities. Oncotarget. 2017;8(15):25721-25735.

13. Xie R, Wang Y, Nie W, et al. Lin28B expression correlates with aggressive clinicopathological characteristics in breast invasive ductal carcinoma. Cancer Biother Radiopharm. 2014;29(5):215-220.

14. Balzeau J, Menezes MR, Cao S, Hagan JP. The LIN28/let-7 pathway in cancer. Front Genet. 2017;8:31.

15. Manier S, Powers JT, Sacco A, et al. The LIN28B/let-7 axis is a novel therapeutic pathway in multiple myeloma. Leukemia. 2017;31(4): 853-860.

16. Peng F, Li TT, Wang KL, et al. H19/let-7/LIN28 reciprocal negative regulatory circuit promotes breast cancer stem cell maintenance. Cell Death Dis. 2017;8(1):e2569.

17. Feng $\mathrm{C}$, Neumeister $\mathrm{V}, \mathrm{Ma} \mathrm{W}$, et al. Lin 28 regulates HER 2 and promotes malignancy through multiple mechanisms. Cell Cycle. 2012;11(13): 2486-2494.

18. Sakurai M, Miki Y, Masuda M, et al. Lin28: a regulator of tumorsuppressing activity of let-7 microRNA in human breast cancer. J Steroid Biochem Mol Biol. 2012;131(3-5):101-106.
OncoTargets and Therapy

\section{Publish your work in this journal}

OncoTargets and Therapy is an international, peer-reviewed, open access journal focusing on the pathological basis of all cancers, potential targets for therapy and treatment protocols employed to improve the management of cancer patients. The journal also focuses on the impact of management programs and new therapeutic agents and protocols on

\section{Dovepress}

patient perspectives such as quality of life, adherence and satisfaction The manuscript management system is completely online and includes a very quick and fair peer-review system, which is all easy to use. Visit http://www.dovepress.com/testimonials.php to read real quotes from published authors. 